\title{
¿Es importante publicar durante la etapa de formación en Dermatología?
}

\section{Is it important to publish during Dermatology training?}

Hace algunos meses, nos encontramos ante una tarea desafiante: conformar la Sección de Dermatólogos Jóvenes de esta prestigiosa revista. Sabíamos que iba a ser nuestro primer encuentro formal con la actividad científica $y$, con entusiasmo, pusimos "manos a la obra".

Las revistas científicas ocupan un lugar prioritario en la educación médica continua de grado y de posgrado. Durante la formación como especialistas, el acto de preparar un artículo para publicar enriquece la formación académica, no solo porque requiere una amplia revisión y estudio sobre una temática, sino también porque ejercita la actualización constante, amplía el conocimiento y estimula el desafío de investigar.

En el proceso, pueden surgir dificultades que deben tenerse presentes para poderlas afrontar. Es habitual que en los establecimientos educativos médicos, la formación esté principalmente abocada a las competencias adquiridas mediante la tarea asistencial, por lo cual se resignan la docencia y la investigación. Asimismo, el empleo de una lengua extranjera, ya sea durante la búsqueda bibliográfica o en el momento de la redacción del manuscrito, puede ser una limitación para muchos autores, desmotivar al dermatólogo en formación y repercutir negativamente en el acceso a información fundamental.

Frente a esta situación, destacamos que la actividad científica durante la instancia formativa debe contar con un tiempo protegido y con el asesoramiento de residentes superiores, instructores y tutores con experiencia. Ellos deben garantizar la adquisición de los recursos necesarios para poder investigar y llevar a cabo esa tarea.

Para finalizar, queremos incentivar y, al mismo tiempo, invitar a todos los jóvenes que están en el período de formación, a emprender la gratificante tarea de escribir artículos que contribuyan a afianzar los conocimientos propios, de los colegas o de otros profesionales también en formación. Como equipo de dermatólogas jóvenes, estamos a disposición de quienes deseen hacerlo y ver publicado su trabajo en Dermatología Argentina.

\author{
María Noelia Andrade (Córdoba) \\ Laura Cantú Parra (Mendoza) \\ Tatiana Giselle Nógalo (Tucumán) \\ Sección Dermatólogos Jóvenes \\ Dermatología Argentina
}

